\title{
Surgical treatment of non-functioning pituitary macroadenomas by the endoscopic endonasal approach in the elderly
}

\author{
Tratamento cirúrgico dos macroadenomas não secretores de hipófise por via endoscópica \\ endonasal em idosos
}

Horacio Armando Marenco1,3, Samuel Tau Zymberg',2, Rodrigo de Paula Santos ${ }^{1,4}$, Cláuder Oliveira Ramalho

\begin{abstract}
Over the past three decades, surgical series of elderly patients treated for pituitary adenomas have been published, all of which used the microscopic transsphenoidal or transcranial approach. The objective of this study was to retrospectively analyze the surgical results of our first 25 elderly patients with non-functioning pituitary macroadenoma (NFPM) operated by the endoscopic endonasal approach (EEA). Preoperative visual loss was found in $92.8 \%$ of the cases, and $70.8 \%$ experienced visual improvement following surgery. Preoperative pituitary dysfunction was found in $69.2 \%$ of the cases and postoperative pituitary recovery occurred in $22.2 \%$ of them. Mean hospital stay was 6.7 days. The results of this study suggest that surgery remains the first line of treatment for NFPM in the elderly. Because age alone is not a barrier for surgery, patients should be selected for surgical treatment based on their symptoms and clinical condition, as defined by comorbidities.
\end{abstract}

Keywords: aged, pituitary neoplasms, pituitary diseases, endoscopic surgical procedures.

\begin{abstract}
RESUMO
Nas últimas três décadas, foram publicadas casuísticas de pacientes idosos operados por adenomas de hipófise, nas quais foram utilizadas as vias transcraniana ou transesfenoidal microcirúrgicas. O objetivo deste estudo foi analisar retrospectivamente os resultados dos nossos primeiros 25 pacientes idosos com macroadenomas não secretores de hipófise, operados pela via endoscópica endonasal. 0 déficit visual pré-operatório foi encontrado em 92,8\% dos casos e 70,8\% apresentaram melhora da visão depois da cirurgia. 0 hipopituitarismo pré-operatório foi encontrado em $69,2 \%$ dos casos e a sua recuperação ocorreu em 22,2\% destes casos. A estadia hospitalar média foi de 6,7 dias. Este estudo sugere que a cirurgia permanece como o tratamento de primeira escolha para pacientes idosos com macroadenomas não secretores de hipófise e a idade por si só não é contraindicação para cirurgia.
\end{abstract}

Palavras-chave: idosos, neoplasias hipofisárias, doenças da hipófise, procedimentos cirúrgicos endoscópicos.

Life expectancy has continued to increase in most developed countries over the past two centuries. It is estimated that three-quarters of all infants born since 2000 will live to an age of 75 years, whereas more than half of these infants will reach 100 years ${ }^{1}$. The life expectancy in Brazil has increased over the last century at a rate similar to that in most developed countries ${ }^{2}$. Aging populations lead to more elderly patients presenting neurosurgical problems; pituitary adenomas are a common finding in this age group, as has already been observed in a series of autopsies of elderly individuals ${ }^{3}$.
Over the past three decades, several authors have published surgical series of elderly patients treated for pituitary adenomas, which account for $1.2 \%$ to $9 \%$ of all patients in the reported series ${ }^{4,5,6,7,8,9}$. This proportion increases to $14.6 \%$ if only non-functioning pituitary adenomas are considered ${ }^{10}$. Non-functioning pituitary adenomas are usually diagnosed as macroadenomas in elderly patients, at which point the adenomas become clinically relevant due to the local mass effect ${ }^{9,10,11}$. In these cases, because surgery provides decompression of the optic chiasm and may permit some degree of

\footnotetext{
${ }^{1}$ Universidade Federal de São Paulo, Programa de Pós-Graduação em Otorrinolaringologia e Cirurgia da Cabeça e Pescoço, Departamento de Otorrinolaringologia, Sao Paulo SP, Brazil;

${ }^{2}$ Universidade Federal de São Paulo, Departamento de Neurocirurgia, Sao Paulo SP, Brazil;

${ }^{3}$ Fundação Leonor de Barros Camargo, Hospital Augusto de Oliveira Camargo, Serviço de Neurocirurgia, Indaiatuba SP, Brazil;

«Universidade Federal de São Paulo, Departamento de Otorrinolaringologia, Setor de Rinologia, Sao Paulo SP, Brazil.

Correspondence: Horacio Armando Marenco;Av. Francisco de Paula Leite, 399; 13344-700 Indaiatuba SP, Brasil; E-mail: horacio.marenco@gmail.com

Conflict of interest: There is no conflict of interest to declare

Received 19 March 2015; Received in final form 17 April 2015; Accepted 07 May 2015.
} 
endocrinological recovery, the first line of treatment is surgery rather than radiotherapy or medical treatment ${ }^{6,10}$. Some authors suggest that due to the elevated risks of surgery in the elderly, the sole indication for surgical treatment of pituitary adenomas in this population should be macroadenoma with mass effect and visual impairment ${ }^{11}$.

In our series, radiotherapy was reserved for the treatment of the postoperative regrowth of tumor remnants. After reviewing the current literature, we have identified three series dedicated exclusively to the surgical treatment of non-functioning pituitary macroadenomas (NFPM) in the elderly ${ }^{10,12,13}$, all of which used the microscopic transsphenoidal or transcranial approach. In this article, we review our experience with the first 25 patients older than 65 years at time of surgery who were operated upon for NFPM by the endoscopic endonasal approach (EEA).

\section{METHOD}

Between March 2001 and July 2013, 369 patients underwent surgery for sellar lesions in our Neurosurgery department. Of these patients, 44 were identified as being older than 65 years at the time of surgery (11.9\%). For this study, we selected all 25 patients who presented with histologically confirmed NFPM and who were treated with EEA. One patient with unavailable medical records and three who were treated by the microscopic transsphenoidal approach were excluded.

The present study was approved by the Committee on Ethics in Research of the Federal University of São Paulo under the record 733.100 (July 30, 2014). All of the data from patients were carefully anonymized despite the informed consent form provided to all patients who remained in follow-up.

There were 14 (56\%) female patients and 11 (44\%) male patients; the mean age was 72.4 years. The physiological status of the patients was graded according to the American Society of Anesthesiologists (ASA) scale ${ }^{14}$.

All of the patients underwent detailed radiological studies with preoperative sellar MRI and were classified according to the system proposed by Ludecke ${ }^{15}$. The first postoperative MRI, one to three months after surgery, determined the degree of resection. Data about tumor resection degree were not available in two cases (Table).

The endocrinological evaluation of the patients included pre- and postoperative serum levels of GH, IGF-1, ACTH, cortisol, PRL, TSH, FT4, FSH, LH and, for males, testosterone. The specimens that were resected during surgery underwent microscopic routine histological analysis, and most underwent immunohistochemical analysis using the HRP-StreptAvidin Biotin method.

The patients had their visual deficits evaluated in our Ophthalmology department both pre- and postoperatively; in some cases, campimetry was performed elsewhere. Two patients were operated upon twice due to tumor remnant regrowth and a new visual deficit. A third patient was operated upon twice due to tumor remnant regrowth on control MRI without visual deficit. Subsequently, the sample increased to 28 surgical procedures across 25 patients. The follow-up time of our patients ranged from 11 to 132 months, with a mean duration of 47.2 months.

All of the data were analyzed using the software R Core Team (2014) (R Foundation for Statistical Computing, Vienna, Austria). Normal distribution of obtained data was evaluated using Shapiro-Wilk test. Fisher's exact test was used for analysis of the correlation between the categorical variables. Student t-test and Mann-Whitney test were used for the analysis of correlations between categorical and numerical variables when appropriate. P-values $<0.05$ were considered to be statistically significant.

\section{RESULTS}

\section{Clinical presentation}

Visual loss was the most common symptom, affecting 24 out of 25 patients prior to the first surgical procedure and two out of three patients who underwent a second surgery (92.8\%). The second most common symptom was headache, which was present in 12 of the 28 cases (42.8\%).

Less common symptoms included dizziness, weight loss, seizure and libido reduction. Three patients were diagnosed with pituitary macroadenomas during investigation for dementia with magnetic resonance image (MRI)

Table. Patient details.

\begin{tabular}{|c|c|}
\hline Characteristic & No. \\
\hline Total no. of patients & 25 \\
\hline Total no. of surgical procedures & 28 \\
\hline Male : Female & $11: 14$ \\
\hline \multicolumn{2}{|l|}{ Age (years) } \\
\hline Mean \pm SD & $72.4 \pm 4.7$ \\
\hline Range & $65-79$ \\
\hline \multicolumn{2}{|l|}{ ASA score } \\
\hline 1 & 1 \\
\hline 2 & 19 \\
\hline 3 & 8 \\
\hline $4 / 5$ & 0 \\
\hline \multicolumn{2}{|l|}{ Tumor size* } \\
\hline T1 & 0 \\
\hline $\mathrm{T} 2$ & 1 \\
\hline T3 & 9 \\
\hline $\mathrm{T} 4$ & 13 \\
\hline Range (mm) & $17-48$ \\
\hline Mean $\pm S D(m m)$ & $34 \pm 7.3$ \\
\hline Invasion of adjacent structures & $20 / 27(74.1 \%)$ \\
\hline Visual deficit & $26 / 28(92.8 \%)$ \\
\hline Preoperative hypopituitarism & $18 / 26(69.2 \%)$ \\
\hline
\end{tabular}

maximal diameter:T1, up to $9 \mathrm{~mm}$ :T2:10-20 mm;T3,21-30 mm;T4,31 mm or more. 
or computerized tomography. One patient was admitted to emergency care due to pituitary apoplexy with acute visual loss and unilateral palpebral ptosis. The duration of the symptoms varied from six months to eight years until diagnosis.

Chronic comorbid diseases were listed for each case before surgery, and the ASA score was retrieved from the anesthesiologist's record. We found that most patients presented at least one chronic disease. Arterial hypertension was the most prevalent comorbidity, present in $92.9 \%$ of the patients. Diabetes was present in $35.7 \%$ of the patients, myocardial disease in $25 \%$, dementia in $14.2 \%$, chronic pulmonary disease in $7.1 \%$, and cancer in $7.1 \%$.

According to the ASA scale, $3.6 \%$ of the patients were classified as grade $1,67.8 \%$ as grade 2 and $28.6 \%$ as grade 3 . There were no grade 4 or 5 classified patients within this series.

\section{Surgical outcome}

All of the patients were operated upon by EEA, as described in detail previously ${ }^{16}$. Neuronavigation was not available for any case. The mean operative time was $146 \pm 43$ minutes, as determined by the anesthesiologist's records. Our multidisciplinary team performed all of the procedures. In addition, training neurosurgery and otorhinolaryngology residents and an observing endocrinology resident also participated; these residents would later assist the patient in the ward.

The results regarding visual deficits due to tumor compression of the optic pathways were available in 26 cases. Twenty-four cases presented visual loss preoperatively, and 17 (70.8\%) of these patients experienced visual improvement following surgery; the other patients showed no change. Statistical analysis showed no relation between total tumor resection and postoperative visual improvement ( $p=0.151)$. There were no new cranial nerve dysfunctions or worsening visual deficits related to the surgical procedures. One patient with preoperative unilateral VI nerve dysfunction and one with unilateral III nerve dysfunction improved after surgery.

Cerebrospinal fluid (CSF) fistulae occurred in only one patient, who also presented with bacterial meningitis and seizures and required antibiotic treatment. A second endoscopic endonasal procedure was necessary to close the fistulae. This patient had a postoperative stay of 46 days, the longest hospitalization in our series, after which he was discharged to his home. The mean hospitalization time was 6.7 days (range: 1 - 46 days).

One major bleeding event requiring transfusion, in the same patient who presented CSF fistulae, was the only intraoperative complication among our cases. Mild epistaxis occurred in four cases during the first three days after surgery, although no special care was required. One patient presented moderate epistaxis ten days following surgery related to Ginkgo biloba use and required nasal endoscopic cauterization. Systemic postoperative complications included three cases of electrolyte imbalance, three cases of delirium and one case of symptomatic hypotension, all of them transient.
There was one death in our series. A 73-year-old woman with a 45-mm pituitary adenoma was operated upon uneventfully. However, this patient died due to the decompensation of an existing cardiac insufficiency four days following surgery, resulting in a $3.6 \%$ mortality rate in this series.

Total tumor resection was achieved in $30.8 \%$ of the cases, subtotal resection in $34.6 \%$ and partial resection in $34.6 \%$ (Figure 1). Total tumor resection was not related to tumor size $(p=0.328)$ or invasion of the cavernous sinus $(p=0.145)$ in this series.

The application of postoperative fractionated stereotactic radiotherapy was reserved for patients who presented with recurrence of the NFPM and were not good candidates for an additional surgical procedure. In our series, five patients with partial tumor resection and one with subtotal tumor resection presented regrowth of tumor remnants on MRI, which we considered as recurrence. Three patients were operated upon again; no signs of recurrence were observed in two of these patients after five years of follow-up. One patient who presented recurrence of the tumor seven months after the second surgery received radiotherapy. Another two patients received radiotherapy to treat recurrences of a stable tumor remnant after three years of follow-up. One female patient who showed signs of recurrence on MRI five years after surgery without visual loss and at the age of 84 years refused further treatment.

\section{Endocrinological outcome}

Pituitary dysfunction was investigated prior to each surgery. We found a deficiency of at least one pituitary axis in $69.2 \%$ of the cases, and $11.5 \%$ of cases presented mild hyperprolactinemia. Details regarding preoperative anterior pituitary dysfunction are specified in Figure 2.

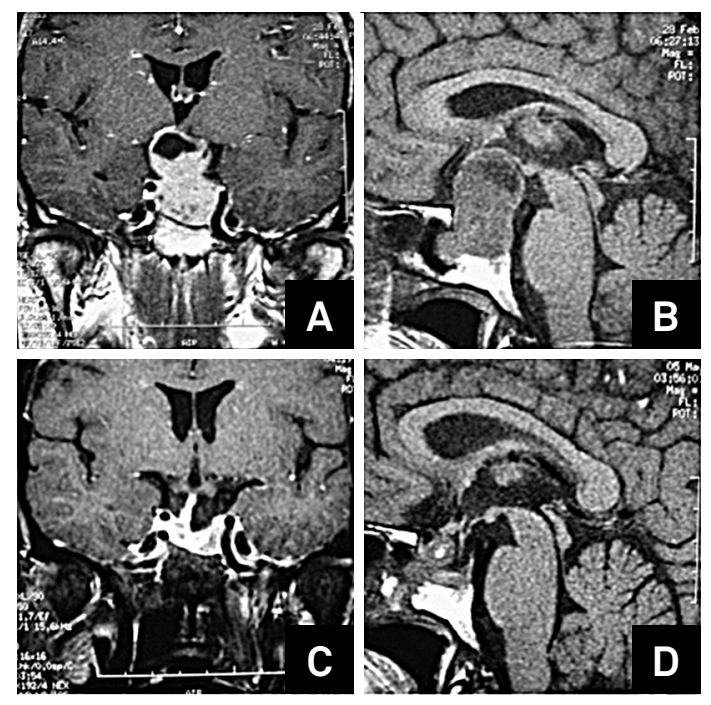

Figure 1. Coronal enhanced and sagittal non-enhanced preoperative magnetic resonance image (MRI) of a non-functioning pituitary macroadenomas case (A and B). Postoperative MRI showing tumor removal (C and D). 


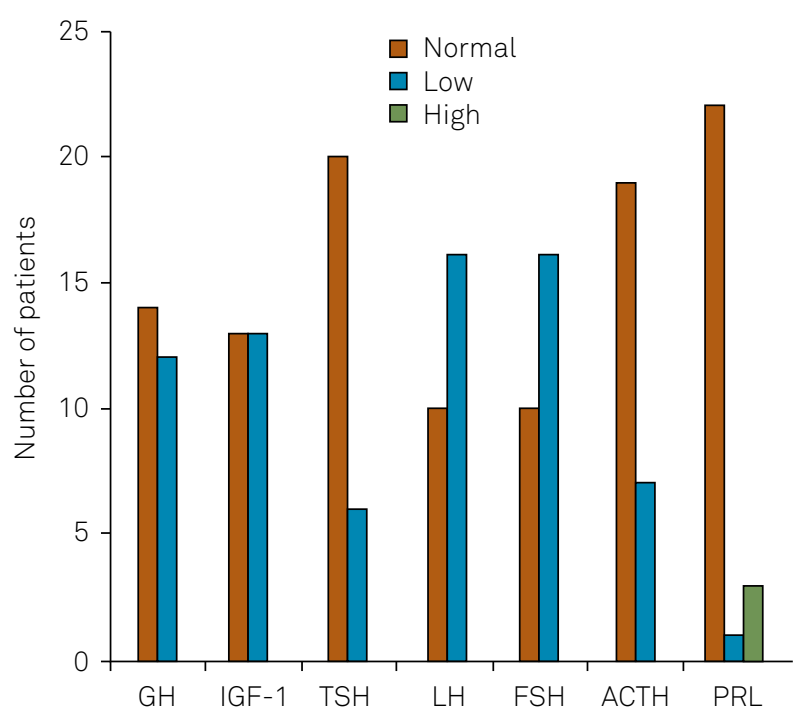

Figure 2. Preoperative serum hormone levels.

One to three months after each surgery, new serum hormone levels were obtained, and anterior pituitary function was re-assessed. There was a new postoperative deficiency of IGF-1 and LH/FSH serum levels in one patient, TSH deficiency in one patient and deficiency of LH/FSH in another patient. All three patients with hyperprolactinemia had normal prolactin levels after the surgery, even those with only partial resection of their tumors.

Recovery from preoperative anterior pituitary insufficiency occurred in four of the 18 cases, which accounted for $22.2 \%$ of the cases (Figure 3 ).

Postoperative diabetes insipidus occurred in $11.5 \%$ of the cases, with none of these events lasting more than five days.

\section{Histological analysis}

Microscopic histological analysis confirmed typical pituitary adenomas in all cases, with one being acidophilic and the rest being chromophobic. Immunohistochemical analysis by the HRP-StreptAvidin Biotin method was available in 20 of the 25 patients. Ki-67 antigen labeling index positivity of $1-3 \%$ was found in most cases, and another two cases presented up to $5 \%$ positivity.

According to the WHO classification of pituitary tumors ${ }^{17}$, the results of our histological and immunohistochemical analysis revealed 11 gonadotropin-producing adenomas, 8 null cell adenomas and 1 silent corticotroph adenoma.

\section{DISCUSSION}

Our data analysis demonstrates that the majority of the patients were diagnosed with NFPM in a late stage of the disease. More than $56 \%$ of the tumors were diagnosed as T4 $(31 \mathrm{~mm}$ or more), whereas $30 \%$ were diagnosed as giant adenomas (40 $\mathrm{mm}$ or more) at presentation. Preoperative MRI showed

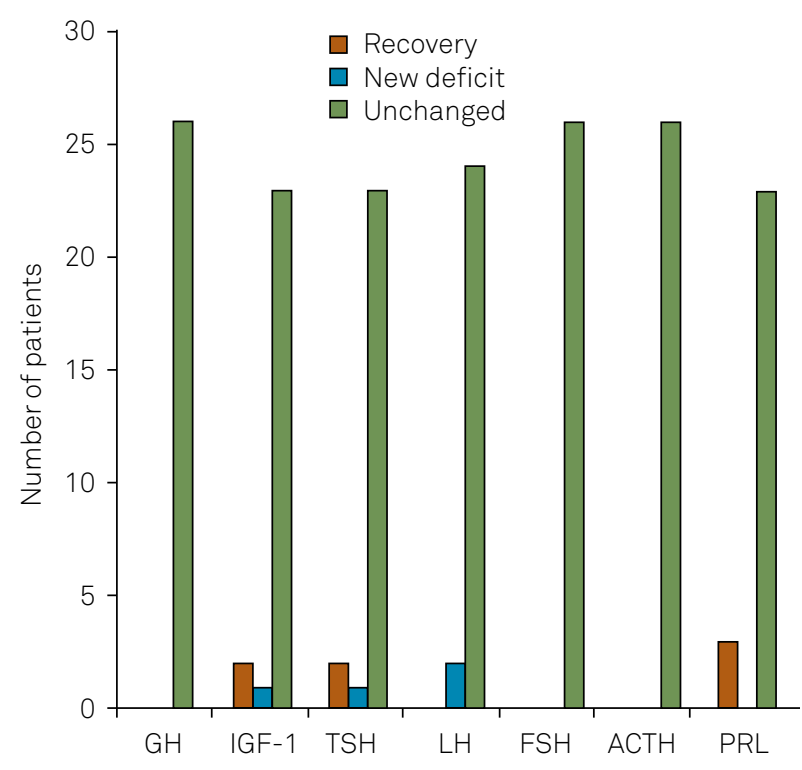

Figure 3. Postoperative serum hormone levels.

$74.1 \%$ of the patients with cavernous sinus invasion. The mean tumor size in our series was $34 \mathrm{~mm}$. This result indicates that we operated upon large invasive tumors in most cases; these findings are similar to those reported by others ${ }^{10,13}$.

Preoperative evaluations demonstrated a $69.2 \%$ prevalence of hypopituitarism. Most of the affected pituitary axes were gonadotrophic, with low LH/FSH levels in $61.5 \%$ of the cases, as well as somatotrophic, with low IGF-1 levels in 50\% of the cases. These findings are similar to the other reports of NFPM in elderly patients ${ }^{10,13}$. The adrenocorticotrophic and thyrotrophic axes were deficient in $26.9 \%$ and $23 \%$ of the cases, respectively. Because pituitary dysfunction is related to the compression of normal pituitary tissue by the tumor mass ${ }^{18}$, a high incidence of hypopituitarism can be expected in a series of patients harboring large adenomas, such as is reported here.

The clinical manifestation of hypopituitarism is frequently unrecognized in elderly patients because it may be confused with the ageing process or masked by chronic conditions common to this age group ${ }^{5,9,13}$. This fact is of great concern given that untreated hypothyroidism and hypocortisolism are themselves life-threatening conditions, aside from all of the symptoms that the patients suffer. Medical treatment with oral hormone replacement is mandatory in these cases because the symptoms and overall clinical condition can be improved despite the NFPM ${ }^{13}$. When appropriate, patients in this series received prednisone, levothyroxine and testosterone injections to treat their hormone deficits.

Because cataracts, retinal degeneration and amblyopia are common visual disturbances in the elderly ${ }^{19}$, visual deficits related to compression of optic pathways by the NFPM can also go unrecognized in the elderly because they may be attributed to other visual conditions ${ }^{9,13}$.

Considering that NFPMs in the elderly are primarily slow-growing lesions with a low proliferative index as 
evaluated by the Ki-67 labeling index ${ }^{10,13}$, the long delay in the diagnosis of NFPMs in the elderly may explain the high rate of large and invasive NFPMs found in this population. Some of our patients had symptomatic NFPMs that were diagnosed almost a decade after the initial complaints.

In our patients, we found that $70.8 \%$ of those with visual loss improved after surgical decompression of the chiasm, irrespective of the duration of visual loss. Considering that we did not pursue a radical tumor resection in each case, we achieved a high rate of visual recovery, similar to other authors who performed radical tumor resection ${ }^{7,9,10}$ and who used neuronavigation ${ }^{20}$.

We found that our patients presented less postoperative diabetes insipidus than other series with radical tumor resection $^{7,9,20}$ and those that were characterized by the same surgical strategy ${ }^{6,13}$. New anterior pituitary deficits were lower in our patients than have been previously reported for series consisting exclusively of NFPMs in elderly patients ${ }^{10,13}$. Neither cranial nerve lesion, even transitory, nor visual deficit worsening occurred in this series.

Comparing the postoperative hospital stay with a previous series consisting exclusively of NFPM in the elderly ${ }^{10}$, our patients remained hospitalized less than half the time (6.7 days $\mathrm{x} 16.3$ days). We believe that the EEA may be one determining factor for a shorter postoperative stay when compared with transsphenoidal microsurgery.

CSF fistula is one of the main postoperative issues in pituitary surgery. Despite an incidence as high as $15.9 \%$ of postoperative CSF fistulae in a large series of EEA ${ }^{21}$, we only observed one incidence of this postoperative complication, representing $3.6 \%$. This was achieved by taking advantage of others' experience with closure techniques ${ }^{22}$, strictly following the surgical technique as developed by our group ${ }^{16}$ and not pursuing radical tumor excision.

One patient died in the early postoperative period from the decompensation of a previous cardiac insufficiency. Although this patient was classified as ASA grade 3 and was theoretically fit for surgical treatment, this case highlights the impact of patient comorbidities on surgical outcome and mortality, as was observed in the largest published analysis on pituitary surgery in the elderly, which found a $3.8 \%$ mortality rate $\mathrm{e}^{23}$.

Recurrences were observed in only $21.4 \%$ of the patients despite a $69.2 \%$ rate of subtotal and partial tumor resection.
This result is in accordance with the low proliferative index of the NFPMs found in our samples and with the observations of other authors, who have also reported low rates of tumor remnant regrowth in elderly patients ${ }^{7,9,10,13}$.

Due to the slow-growing nature of the NFPM in the elderly, postoperative radiotherapy was not routinely indicated because it is associated with complications such as hypopituitarism and optic neuropathy, even with modern application protocols ${ }^{24}$. This modality of treatment was reserved for documented recurrences in patients who were not fit for another surgery.

The low rate of recurrence in our series suggests that not pursuing radical tumor resection at all costs is a good strategy given that subtotal tumor resection can be "curative" in the case of an elderly patient with an NFPM while avoiding surgical morbidity.

In conclusion, this study suggests that surgery should remain the first line of treatment for NFPMs in the elderly. Because age alone is not a barrier for surgery, patients should be selected for surgical treatment based on their symptoms and clinical condition, as defined by comorbidities. Local mass effect of the NFPM with visual loss is the best indication for surgical treatment. Pituitary insufficiency alone is not an indication for surgical treatment because the postoperative recovery is poor and medical therapy can easily resolve this issue. Radical tumor resection should not be the goal in the case of an elderly patient with an NFPM given that visual deficit improvement is not related to total tumor resection and recurrences are low even with incomplete resections. EEA provided similar visual deficit outcomes as transsphenoidal microsurgery but with shorter hospital stays and better results for CSF fistulae, diabetes insipidus and postoperative pituitary deficits.

\section{ACKNOWLEDGEMENTS}

We thank Mr. Matthew John Robbins for his helpful revision of the manuscript, Prof. Gianni Mara Silva dos Santos from the Department of Statistics of the Federal University of São Paulo for her assistance with the statistical analysis and Prof. Dr. Julio Zaki Abucham Filho and the Department of Endocrinology of the Federal University of São Paulo for the caring of the patients included in this study.

\section{References}

1. Christensen K, Doblhammer G, Rau R, Vaupel JW. Ageing populations: the challenges ahead. Lancet. 2009;374(9696):1196-208. doi:10.1016/S0140-6736(09)61460-4

2. Ramos LR, Veras RP, Kalache A. Envelhecimento populacional: uma realidade brasileira. Rev Saude Publica. 1987;21(3):211-24. doi:10.1590/S0034-89101987000300006

3. Kovacs K, Ryan N, Horvath E, Singer W, Ezrin C. Pituitary adenomas in old age. J Gerontol. 1980;35(1):16-22. doi:10.1093/geronj/35.1.16
4. Cohen DL, Bevan JS, Adams CB. The presentation and management of pituitary tumours in the elderly. Age Ageing. 1989;18(4):247-52. doi:10.1093/ageing/18.4.247

5. Turner HE, Adams CB, Wass JA. Pituitary tumours in the elderly: a 20 year experience. Eur J Endocrinol. 1999;140(5):383-9. doi:10.1530/eje.0.1400383

6. Fraioli B, Pastore FS, Signoretti S, De Caro GM, Giuffrè R. The surgical treatment of pituitary adenomas in the eighth decade. Surg Neurol. 1999;51(3):261-66. doi:10.1016/S0090-3019(98)00097-4 
7. Ferrante L, Trillò G, Ramundo E, Celli P, Jaffrain-Rea ML, Salvati $M$ et al. Surgical treatment of pituitary tumors in the elderly: clinical outcome and long-term follow-up. J Neurooncol. 2002;60 (2):185-91. doi:10.1023/A:1020652604014

8. Sheehan JM, Douds GL, Hill K, Farace E. Transsphenoidal surgery for pituitary adenoma in elderly patients. Acta Neurochir (Wien). 2008;150(6):571-74. doi:10.1007/s00701-008-1581-2

9. Hong J, Ding X, Lu Y. Clinical analysis of 103 elderly patients with pituitary adenomas: transsphenoidal surgery and follow-up. J Clin Neurosci. 2008;15(10):1091-5. doi:10.1016/j.jocn.2007.11.003

10. Kurosaki M, Lüdecke DK, Flitsch J, Saeger W. Surgical treatment of clinically nonsecreting pituitary adenomas in elderly patients. Neurosurgery. 2000;47(4):843-8. doi:10.1097/00006123-200010000-00009

11. Freda PU, Bruce JN. Surgery: risks of pituitary surgery in the elderly. Nat Rev Endocrinol. 2010;6(11):606-8. doi:10.1038/nrendo.2010.170

12. Pospiech J, Stolke D, Pospiech FR. Surgical treatment of pituitary adenomas in elderly patients. Acta Neurochir Suppl. 1996;65:35-6.

13. Del Monte P, Foppiani L, Ruelle A, Andrioli G, Bandelloni R, Quilici $P$ et al. Clinically non-functioning pituitary macroadenomas in the elderly. Aging Clin Exp Res. 2007;19(1):34-40. doi:10.1007/BF03325208

14. Cullen SC. Cybernesthesia. Anesthesiology. 1963;24(1):110-111.

15. Lüdecke DK. Value of transcavernous surgery in the treatment of pituitary adenomas. Eur J Endocrinol. 1995;133(2):147-8. doi:10.1530/eje.0.1330147

16. Santos RP, Zymberg ST, Abucham Filho JZ, Gregório LC, Weckx LL. Endoscopic transnasal approach to sellar tumors. Braz J Otorhinolaryngol. 2007;73(4):463-75.

17. Asthagiri A, Lopes MBS. Neuropathological considerations of pituitary adenomas. In: Laws ER Jr, Sheehan JP, editors. Pituitary surgery: a modern approach. frontiers of hormone research. Basel: Karger; 2006. (Frontiers of hormone research, Vol. 34). p. 206-35.

18. Arafah BM. Reversible hypopituitarism in patients with large nonfunctioning pituitary adenomas. J Clin Endocrinol Metab. 1986;62(6):1173-9. doi:10.1210/jcem-62-6-1173

19. Tielsch JM, Sommer A, Witt K, Katz J, Royall RM. Blindness and visual impairment in an American urban population: the Baltimore eye survey. Arch Ophthalmol. 1990;108(2):286-90. doi:10.1001/archopht.1990.01070040138048

20. Locatelli M, Bertani G, Carrabba G, Rampini P, Zavanone M, Caroli $M$ et al. The trans-sphenoidal resection of pituitary adenomas in elderly patients and surgical risk. Pituitary. 2013;16(2):146-51. doi:10.1007/s11102-012-0390-z

21. Kassam AB, Prevedello DM, Carrau RL, Snyderman CH, Thomas A, Gardner P et al. Endoscopic endonasal skull base surgery: analysis of complications in the authors' initial 800 patients. J Neurosurg. 2011;114(6):1544-68. doi:10.3171/2010.10.JNS09406

22. Hadad G, Bassagasteguy L, Carrau RL, Mataza JC, Kassam A, Snyderman $\mathrm{CH}$ et al. A novel reconstructive technique after endoscopic expanded endonasal approaches: vascular pedicle nasoseptal flap. Laryngoscope. 2006;116(10):1882-6. doi:10.1097/01.mlg.0000234933.37779.e4

23. Grossman R, Mukherjee D, Chaichana KL, Salvatori R, Wand G, Brem $\mathrm{H}$ et al. Complications and death among elderly patients undergoing pituitary tumour surgery. Clin Endocrinol (Oxf). 2010;73(3):361-8. doi:10.1111/j.1365-2265.2010.03813.x

24. Weber DC, Momjian S, Pralong FP, Meyer P, Villemure JG, Pica A Adjuvant or radical fractionated stereotactic radiotherapy for patients with pituitary functional and nonfunctional macroadenoma. Radiat Oncol. 2010;6:169. doi:10.1186/1748-717X-6-169 